\title{
Chronic idiopathic thrombocytopenia treated with immunoglobulin
}

\author{
P G MORI, G MANCUSO, D DEL PRINCIPE, M DUSE, R MINIERO, R TOVO, \\ M BARDARE, V CARNELLI, AND D DE MATTIA \\ Department of Paediatric Haematology and Oncology G Gaslini Children's Hospital, Genoa, and \\ the Paediatric Departments of the Universities of Palermo, Rome, Pavia, Turin, Milan, and Bari, Italy
}

SUMmARY Twenty five children with chronic idiopathic thrombocytopenic purpura followed from 6-96 months in 7 Italian paediatric departments were treated with high dose immunoglobulin according to a multicentre protocol. Positive responses were observed in 20 of 25 patients (80\%) and negative responses in 5 of $25(20 \%)$. On previous steroid treatment 7 of 10 positive responders were steroid resistant and 13 of 15 were steroid dependent. Within four weeks of beginning treatment 16 of 20 patients $(80 \%)$ relapsed, while 4 of $20(20 \%)$ maintained normal platelet values after $4-12$ months' follow up. Statistical analysis of the platelet count on day five of treatment enabled us to divide positive responders into three groups: good, intermediate, and poor. The possible mode of action and clinical application of high dose immunoglobulin are discussed.

In 1977 Grassi and Brogi, ${ }^{1}$ and more recently other authors, ${ }^{2-10}$ have shown that immunoglobulin treatment has some effectiveness in idiopathic thrombocytopenic purpura (ITP). In these studies criteria for patient selection (age, acute or chronic phase of disease) and treatment regimens differed. From these trials it emerges that the efficacy of immunoglobulin treatment depends on an intact Fc fragment that reacts with the macrophage $\mathrm{Fc}$ receptor. ${ }^{5}$

This multicentre study was undertaken by the Haemostasis Study Group of the Italian Association of Paediatric Haematology and Oncology and by the Italian Paediatric Immunology Study Group to determine the possible beneficial effect of immunoglobulin (Ig) in children with chronic ITP. A purified and biochemically unmodified Ig preparation Gammabulin vena (Immuno), was used.

\section{Patients and methods}

Twenty six children with chronic ITP, 17 boys and 9 girls, aged between 4 and 14 years, were studied. The results from one patient were excluded because of insufficient data, and only 25 patients were therefore evaluated. In three children the disease was aetiologically related to measles, in one child to

Joint Authors: Boeri E, Rosati U, Tonini G P, Oddo G, Scrivano A M, Menichelli A, Nespoli L, Re R, Fiandino G, Lo Vecchio T, Ciavarella G, Guazzini S. mumps, and in five to a single episode of pharyngotonsillitis.

Criteria for patient selection were persistent thrombocytopenia from more than 6 months, with a platelet count less than $50000 / \mathrm{mm}^{3}$ $\left(50 \times 10^{9} / 1\right)$, and a normal or increased number of megakaryocytes in bone marrow aspirate. Patients were included in this study irrespective of their response (sensitivity or resistance) to previous steroid treatment and splenectomy.

Before entering the study, the children had been followed from 6-96 months (median 51 months). All had been given steroids for 1-6 months, but had stopped this treatment for at least one month before the study. Fifteen were steroid dependent, 10 steroid resistant, and two patients had undergone splenectomy.

The platelet count at the beginning of treatment was mean (SD) $23000 / \mathrm{mm}^{3}\left(12000 / \mathrm{mm}^{3}\right)\left(23 \times 10^{9} / 1\right.$ $\left.\left(12 \times 10^{9} / 1\right)\right)$. White blood cell count, blood urea nitrogen, blood glucose, fibrinogen, and immunoglobulin serum values were monitored on days one, two, and five of treatment, and the day after it ended. Platelet count was performed every other day during the first 10 days, and then weekly. Patients' follow up varied from 4-12 months (median 9 months).

Gammabulin vena is produced from Cohn fraction II by further multiple salting out steps, polyethylene glycol, and iso-electric precipitation. 


\section{Mori, Mancuso, del Principe, Duse, Miniero, Tovo, Bardare, Carnelli, and de Mattia}

This preparation contains at least $90 \%$ of $7 \mathrm{~S}$ protein determined by ultracentrifugal analysis; its anticomplementary activity is low, at least $28 \mathrm{mg}$ Gammabulin vena are needed to inhibit one unit of $\mathrm{CH}_{50}$. The treatment schedule consisted of daily IV injections of $400 \mathrm{mg} / \mathrm{kg}$ of Gammabulin vena in a $5 \%$ glucose solution for five hours, for five consecutive days.

\section{Results}

Eighty per cent of the patients (20 of 25$)$ gave a positive response, while $20 \%$ ( 5 of 25 ) did not respond to the immunoglobulin treatment. On the basis of the platelet count after the fourth and fifth immunoglobulin injection it was possible to divide responsive patients into three groups (Table 1).

Table 1 Classification of positive response patients according to platelet count after the fourth and fifth immunoglobulin (Ig) injection and at follow up

\begin{tabular}{|c|c|c|c|c|c|}
\hline \multirow{2}{*}{$\begin{array}{l}\text { Positive response } \\
\text { group }\end{array}$} & \multirow[t]{2}{*}{ No of patients } & \multirow{2}{*}{$\begin{array}{l}\text { Platelet count } / \mathrm{mm}^{3} \\
\text { after } 4 \mathrm{th} \mathrm{Ig} \\
\text { injection } \\
\text { Mean }(S D)\end{array}$} & \multirow{2}{*}{$\begin{array}{l}\text { Platelet count } / \mathrm{mm}^{3} \\
\text { after } 5 \text { th } \mathrm{Ig} \\
\text { injection } \\
\text { Mean }(S D)\end{array}$} & \multicolumn{2}{|l|}{ Follow up } \\
\hline & & & & Relapsed & $\begin{array}{l}\text { Long term } \\
\text { remission }\end{array}$ \\
\hline Good & 8 & $226125(110160)$ & $195750(10595)$ & $6 / 8$ & $2 / 8$ \\
\hline Intermediate & 8 & $106000(20942)$ & $103200(31839)$ & $7 / 8$ & $1 / 8$ \\
\hline Poor & 4 & $49750(21899)$ & $41667(8505)$ & $3 / 4$ & $1 / 4$ \\
\hline
\end{tabular}

Conversion: Traditional units to $S I$-platelets $100 / \mathrm{mm}^{3} \approx 1 \times 109 / 1$

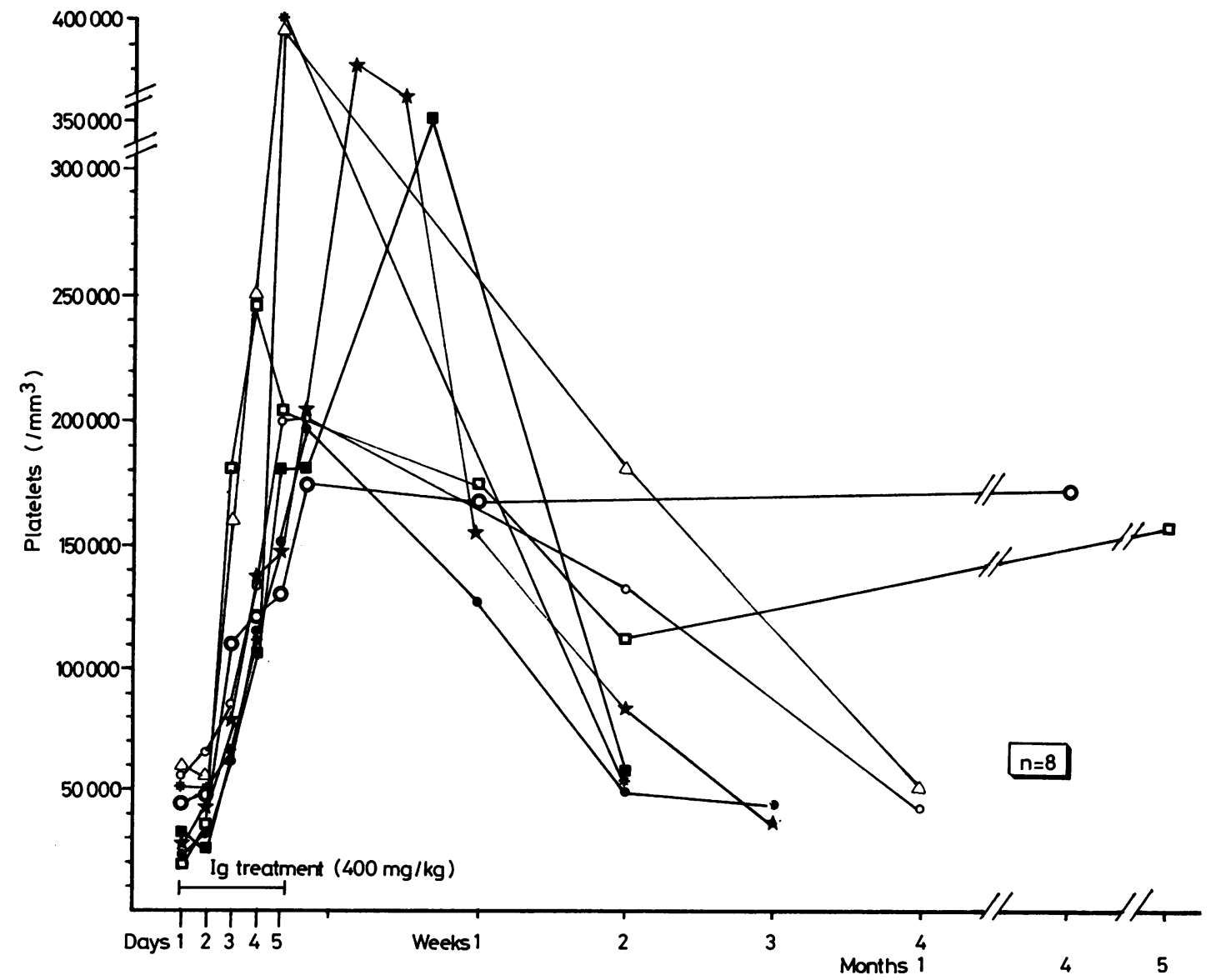

Fig. 1 Platelet count during and after immunoglobulin (Ig) treatment in the 'good response' group. 
(1) Good response-8 patients, (Fig. 1).

(2) Intermediate response-8 patients, (Fig. 2).

(3) Poor response-4 patients, (Fig. 3).

The difference between the means of these groups is statistically significant (Student's $t$ test) (Table 2).
Follow up of the patients showed further differences between the three groups: in fact, poor responders usually had a later increase in platelet count up to mean (SD) $131250 / \mathrm{mm}^{3}$ (36 362) $/ \mathrm{mm}^{3}$ $\left(131 \cdot 25 \times 10^{9} / 1\left(36 \cdot 36 \times 10^{9} / 1\right)\right)$ between days 9 and

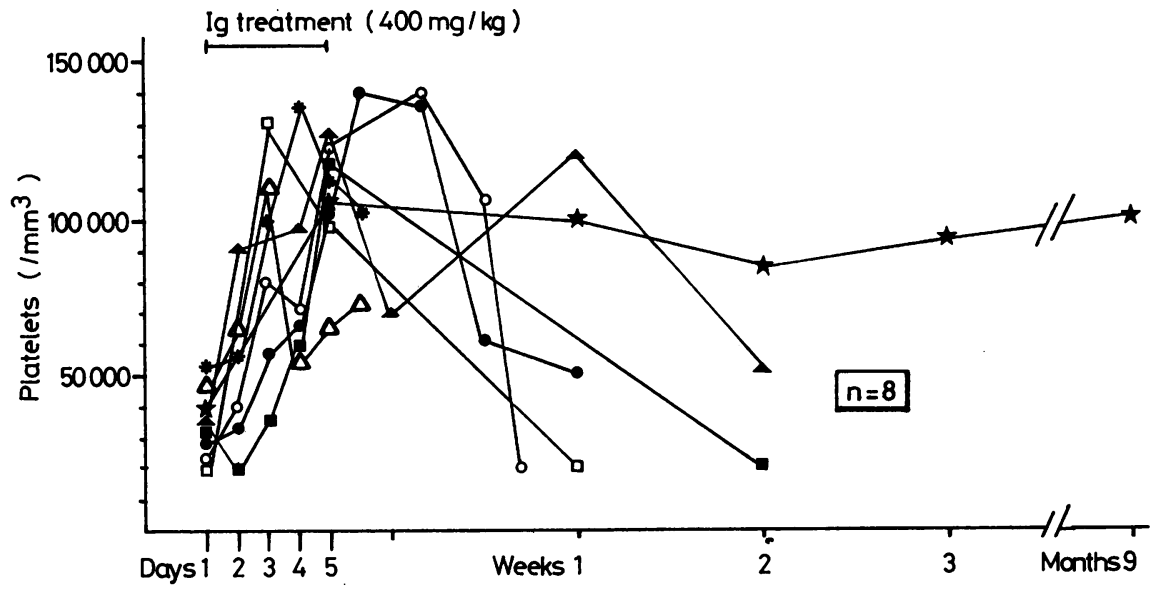

Fig. 2 Platelet count during and after immunoglobulin (Ig) treatment in the 'intermediate response' group.

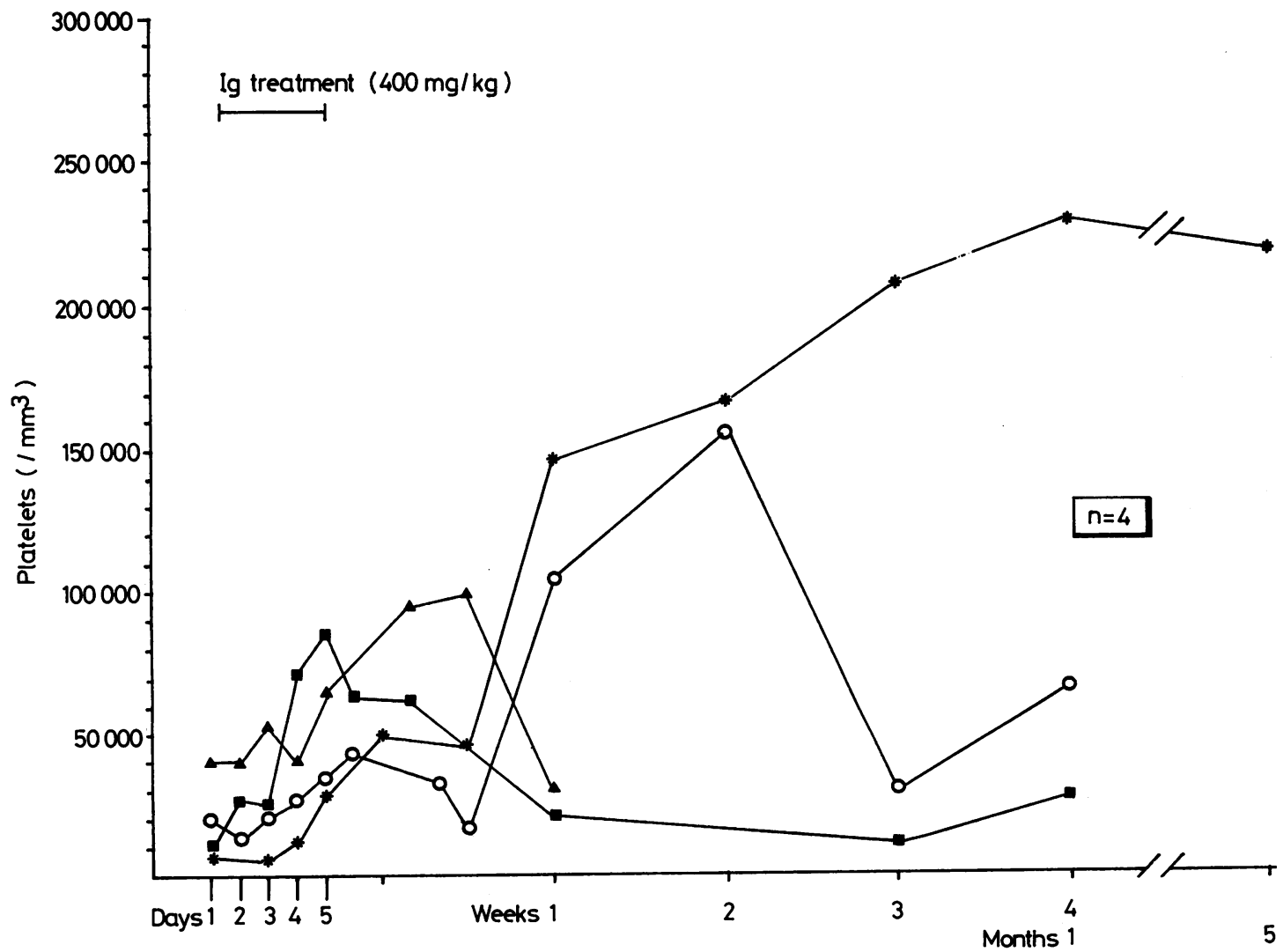

Fig. 3 Platelet count during and after immunoglobulin (Ig) treatment in the 'poor response' group. 
Table 2 Statistical analysis (Student's $t$ test) between good, intermediate, and poor response groups after the 4th and 5th immunoglobulin (Ig) injection

\begin{tabular}{lll}
\hline Group & \multicolumn{1}{c}{ Student's t test } \\
\cline { 2 - 3 } & $\begin{array}{l}\text { After } 4 \text { th } \mathrm{Ig} \\
\text { injection }\end{array}$ & $\begin{array}{l}\text { After } 5 \text { th } \mathrm{Ig} \\
\text { injertion }\end{array}$ \\
\hline $\begin{array}{l}\text { Good response/intermediate } \\
\text { response }\end{array}$ & $3.03, \mathrm{P}<0.01$ & $5.50, \mathrm{P}<0.01$ \\
$\begin{array}{l}\text { Good response/poor response } \\
\begin{array}{l}\text { Intermediate response/poor } \\
\text { response }\end{array}\end{array}$ & $3.09, \mathrm{P}<0.05$ & $20.60, \mathrm{P}<0.01$ \\
\hline
\end{tabular}

14 , so that they may also be called 'late responders', while patients in the first two groups may be termed 'early responders'. Long term follow up after stopping treatment showed that in $85 \%$ of the patients (17 of 20) the platelet count returned to pretreatment values within one to four weeks. In particular, in 6 of 8 good responders the platelet count dropped to pretreatment values after two to four weeks. The two other patients in this group are presently maintaining a platelet count of 100000 and $170000 / \mathrm{mm}^{3}\left(100\right.$ and $\left.170 \times 10^{9} / \mathrm{l}\right)$ after follow up periods of five and four months respectively. In the intermediate response group, 7 patients relapsed within one to two weeks: one reached and maintained a platelet count of $120000 / \mathrm{mm}^{3}\left(120 \times 10^{9} / \mathrm{l}\right)$ after follow up of 9 months. In the poor response group, three patients relapsed within three weeks of stopping treatment; the fourth reached his maximum value of $210000 / \mathrm{mm}^{3}\left(210 \times 10^{9} / \mathrm{l}\right)$ four weeks after treatment and maintained it during all his follow up (five months). In the five unresponsive patients $(20 \%)$, the platelet count remained unchanged after immunoglobulin treatment (Fig. 4).

Treatment was well tolerated. Five patients, treated in the same department, had a transient conjunctivitis. No change in the absolute number of
Table 3 Correlation between steroid sensitivity, positive and negative response, and positive persistent response to immunoglobulin (Ig) treatment in 25 patients.

\begin{tabular}{llll}
\hline Steroid sensitivity & \multicolumn{2}{l}{ Response to Ig treatment } & $\begin{array}{l}\text { Positive } \\
\text { persistent } \\
\text { response }\end{array}$ \\
\hline Dependent $(\mathrm{n}=15)$ & 13 & 2 & 2 \\
Resistant $(\mathrm{n}=10)$ & 7 & 3 & 2 \\
\hline
\end{tabular}

white blood cells, blood urea nitrogen, glucose and fibrinogen serum values was detected. With regard to serum immunoglobulin values the increment of IgG was mean (SD) $878.82(341.94) \mathrm{mg} \%$ between day one and day two, and $1561.91(603.45)$ $\mathrm{mg} \%$ between day one and day five of treatment. IgA and IgM values were not affected. No correlation was observed between previously assessed steroid sensitivity and response to immunoglobulin treatment, as shown in Table 3.

\section{Discussion}

These results on a large series of patients enable us to make some important clinical suggestions and to propose hypotheses. Firstly, the high percentage $(80 \%)$ of positive results obtained and the high platelet counts reached $\left(>100000 / \mathrm{mm}^{3}\left(100 \times 10^{9} / \mathrm{l}\right)\right.$ in 19 of 20 patients) are noteworthy. Secondly, hospital admission is not required for this treatment because of the lack of toxicity and short duration of the treatment. Thirdly, there is no cross resistance between steroid and immunoglobulin treatment; in fact, both steroid sensitive and steroid resistant patients responded positively to immunoglobulin treatment ( $84 \%$ and $75 \%$, respectively). Immunoglobulin treatment has the advantage of a faster response than steroid treatment. In a series of 80 patients with acute ITP treated at G Gaslini

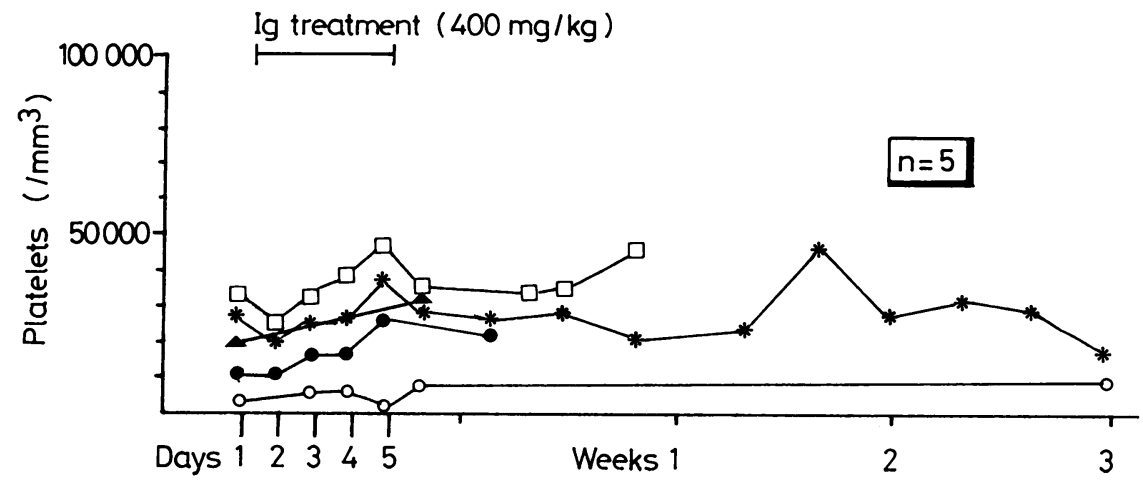

Fig. 4 Platelet count during and after immunoglobulin (Ig) treatment in the 'no response' group. 
Children's Hospital with $2 \mathrm{mg} / \mathrm{kg}$ prednisone, the mean time to reach maximum platelet value in 30 positive responders was 10 days (unpublished data); while in the present study 16 of 20 responsive patients reached maximum response within 5 days.

Immunoglobulin treatment has the disadvantage of a frequent early relapse. In 16 of $20(80 \%)$ patients the platelet count dropped to almost pretreatment values after four weeks. Four children, however, maintained their platelet count within the normal range after a follow up period varying from 4-12 months, and we could consider them definitively cured.

On the basis of these considerations we suggest treatment with immunoglobulin in the following cases:

(1) Where a fast increase in platelet count is required.

(2) Where steroid treatment is not indicated or is ineffective.

(3) As a substitute for immunosuppressive treatment, the use of which should be limited by its adverse effects.

(4) As an attempt to avoid splenectomy.

Our results allowed us to divide patients into groups according to their clinical response. On the basis of the treatment response there were positive or negative responders. Positive responders were themselves divided into three groups according to the degree of increase in the platelet count and to the time taken to obtain a notable response (Table 1). These groups were: good response, intermediate response, and poor response.

After the fourth immunoglobulin injection the difference between the groups was already considerable, but it became more evident after the fifth injection (Table 2).

The possibility of predicting the type of response would be extremely interesting clinically. We carefully examined our 25 patients looking for a correlation between response and: age, sex, anamnesis (with particular attention to exanthematous diseases), duration of thrombocytopenia, results of previous steroid treatment, and platelet count before immunoglobulin treatment. Unfortunately, however, no parameter assumed a predictive value.

The variability of clinical response may be considered as evidence of heterogeneity in the disease. We have no explanation for such biological behaviour, however, and can only hypothesise. According to Fehr ${ }^{5}$, in ITP platelets coated with antiplatelet antibodies are bound to the macrophages through their Fc receptor and then ingested. The presence of an excess of circulating IgG (as in immunoglobulin treatment) would saturate Fc receptors and inhibit platelet binding giving platelet increase. This mechanism may explain the temporary increase in platelets after IgG infusion, but does not explain the lack of response, the persistent normalisation of the platelet count, and the unpredictability of quality of response that we observed after IgG treatment.

At the moment we have no other explanation and we can only suggest that the natural immunological history of ITP may follow distinct phases and that, as a consequence, giving steroids at different times determines the different results observed.

Perhaps ITP is caused by different aetiological and pathological agents, even of non immune origin. In conclusion, immunoglobulin in childhood ITP may not only play an important treatment role in some patients, but provides an opportunity for a new approach to understanding the disease.

We are grateful to Professor Martha Eibl of the Immunology Institute, University of Vien for her scientific advice, to Dr M Pasino and Dr C Rosanda, Department of Paediatric Haematology and Oncology, G Gaslini Children's Hospital of Genoa, for revising the text, and to Immuno for supplying the Gammabulin vena.

\section{References}

1 Grassi A, Brogi M. Le gammaglobuline nella terapia della trombocitopenia. Minerva Pediatr 1977;29:1227-9.

2 Imbach P, Barandun S, Baumgartner C, Hirt A, Hofer F, Wagner HP. High-dose intravenous gammaglobulin therapy of refractory, in particular idiopathic thrombocytopenia in childhood. Helv Paediatr Acta 1981;46:81-6.

3 Imbach P, Barandun S, D'Apuzzo V, et al. High-dose intravenous gammaglobulin for idiopathic thrombocytopenic purpura in childhood. Lancet 1981 ; $\mathbf{i}: 1228-31$.

4 Schmidt RE, Budde U, Schäfer G, Stroehmann I. High-dose intravenous gammaglobulin for idiopathic thrombocytopenic purpura (letter). Lancet 1981 ;i: 475-6.

5 Fehr J, Hofmann V, Kappeler U. Transient reversal of thrombocytopenia in idiopathic thrombocytopenic purpura by high-dose intravenous gamma globulin. $N$ Engl J Med 1982;306:1254-8.

- Schmidt B, Forster J. Increased platelet-associated IgG in child on high-dose gammaglobulin for idiopathic thrombocytopenic purpura. (letter) Lancet 1982 ;ii :39-40.

7 Bierling P, Farcet J P, Duedari N, Rochant H. Increased platelet-associated IgG in patient on high-dose gammaglobulin for autoimmune thrombocytopenic purpura (letter). Lancet $1982 ;$;i: 388.

8 Bierling P, Farcet JP, Duedari N, Rochant H. Gamma globulin for idiopathic thrombocytopenic purpura (letter). $N$ Engl J Med 1982;307:1150.

9 Julia A, Lopez A, Flores A. Gamma globulin for idiopathic thrombocytopenic purpura (letter). $N$ Engl J Med 1982;307:1151.

10 Newland AC, Treleaven JG, Minchinton RM,Waters AH, High-dose intravenous $\mathrm{IgG}$ in adults with autoimmune thrombocytopenia. Lancet 1983 ;i:84-7.

Correspondence to Pier Giorgio Mori, Department of Paediatric Haematology and Oncology, G Gaslini Children's Hospital, Via 5 Maggio 39, 16148 Genova Quarto, Italy

Received 21 June 1983 